Georgia State University

ScholarWorks @ Georgia State University

3-1-2017

\title{
The Role of Public and Private Insurance Expansions and Premiums for Low-Income Parents
}

Gery P. Guy

Emily M. Johnston

Patricia Ketsche

Peter Joski

Follow this and additional works at: https://scholarworks.gsu.edu/ghpc_articles

\section{Recommended Citation}

Guy, Gery P.; Johnston, Emily M.; Ketsche, Patricia; and Joski, Peter, "The Role of Public and Private Insurance Expansions and Premiums for Low-Income Parents" (2017). GHPC Articles. 163.

https://scholarworks.gsu.edu/ghpc_articles/163

This Article is brought to you for free and open access by the Georgia Health Policy Center at ScholarWorks @ Georgia State University. It has been accepted for inclusion in GHPC Articles by an authorized administrator of ScholarWorks @ Georgia State University. For more information, please contact scholarworks@gsu.edu. 


\title{
The Role of Public and Private Insurance Expansions and Premiums for Low-income Parents
}

\author{
Lessons From State Experiences
}

\author{
Gery P. Guy, Jr, PhD, MPH, Emily M. Johnston, PhD, † Patricia Ketsche, PhD, $\ddagger$ Peter Joski, MSPH,* \\ and E. Kathleen Adams, PhD*
}

Background: Numerous states have implemented policies expanding public insurance eligibility or subsidizing private insurance for parents.

Objectives: To assess the impact of parental health insurance expansions from 1999 to 2012 on the likelihood that parents are insured; their children are insured; both the parent and child within a family unit are insured; and the type of insurance.

Design: Cross-sectional analysis of the 2000-2013 March supplements to the Current Population Survey, with data from the Medical Expenditure Panel Survey-Insurance Component and the Area Resource File.

Methods: Cross-state and within-state multivariable regression models estimated the effects of health insurance expansions targeting parents using 2-way fixed effect modeling and difference-indifference modeling. All analyses controlled for household, parent, child, and local area characteristics that could affect insurance status.

Results: Expansions increased parental coverage by 2.5 percentage points, and increased the likelihood of both parent and child being insured by 2.1 percentage points. Substantial variation was observed by type of expansion. Public expansions without premiums and special subsidized plan expansions had the largest effects on parental coverage and increased the likelihood of jointly insuring both the parent and child. Higher premiums were a substantial deterrent to parents' insurance.

Conclusions: Our findings suggest that premiums and the type of insurance expansion can have a substantial impact on the insurance status of the family. These findings can help inform states as they continue to make decisions about expanding Medicaid under the Affordable Care Act to cover all family members.

From the *Rollins School of Public Health, Emory University, Atlanta, GA; $\dagger$ Health Policy Center, Urban Institute, Washington, DC; and †Robinson College of Business, Georgia State University, Atlanta, GA.

This research was funded by grant \#71436 from the Robert Wood Johnson Foundation (RWJF) Changes in Health Care Finance and Organization (HCFO) initiative.

The authors declare no conflict of interest.

Reprints: Gery P. Guy, Jr, PhD, MPH, Rollins School of Public Health, Emory University, 1518 Clifton Road, NE, Atlanta, GA 30322. E-mail: gery.guy@gmail.com.

Copyright @ 2016 Wolters Kluwer Health, Inc. All rights reserved.

ISSN: 0025-7079/17/5503-0236
Key Words: health insurance, Medicaid, state health policy

(Med Care 2017;55: 236-243)

A s Americans continue to gain access to health insurance through the Affordable Care Act (ACA), it is important to consider the impact of state policy choices on insuring not only individuals, but also all family members. Parental insurance status can have important implications for insurance continuity and access to care among their family members. ${ }^{1-5}$ Under the ACA, states retain significant flexibility in terms of eligibility and program structure, including the option to expand Medicaid to all individuals up to $138 \%$ of the federal poverty level (FPL). To date, 25 states and the District of Columbia have chosen to expand the traditional program, whereas 7 states are implementing alternative expansions under Section 1115 waivers. ${ }^{6}$ The remaining 16 states that have not expanded can look at past and current experience in states using these alternative approaches. ${ }^{6}$

In addition to setting Medicaid eligibility levels for covered populations, states have the option to use waivers to provide subsidies for private health insurance. Beginning in 2015, states also have the option to shift to the Basic Health Program (BHP), which allows them to use federal premium tax subsidy funds to reduce the cost of a designated health plan offered outside the Health Insurance Marketplace for individuals with income between 139\% and 200\% FPL. Such plans can improve continuity of coverage for low-income families who experience income instability and may otherwise experience frequent transitions between Medicaid and Marketplace coverage. Beginning in 2017, states will gain the option to implement Section 1332 waivers allowing for further innovation and alternative policies regarding the individual mandate, employer mandate, benefits and subsidies, and the Marketplace and qualified health plans. Understanding the effects of prior state policies can help inform state policy decisions in this new environment of expanded state flexibility in the provision of health insurance for families.

Previous research has shown that health insurance expansions increased public coverage and decreased uninsurance among parents but have not focused on variation by type of expansion. ${ }^{7-13}$ Parental health insurance expansions also have the potential to increase coverage among children 


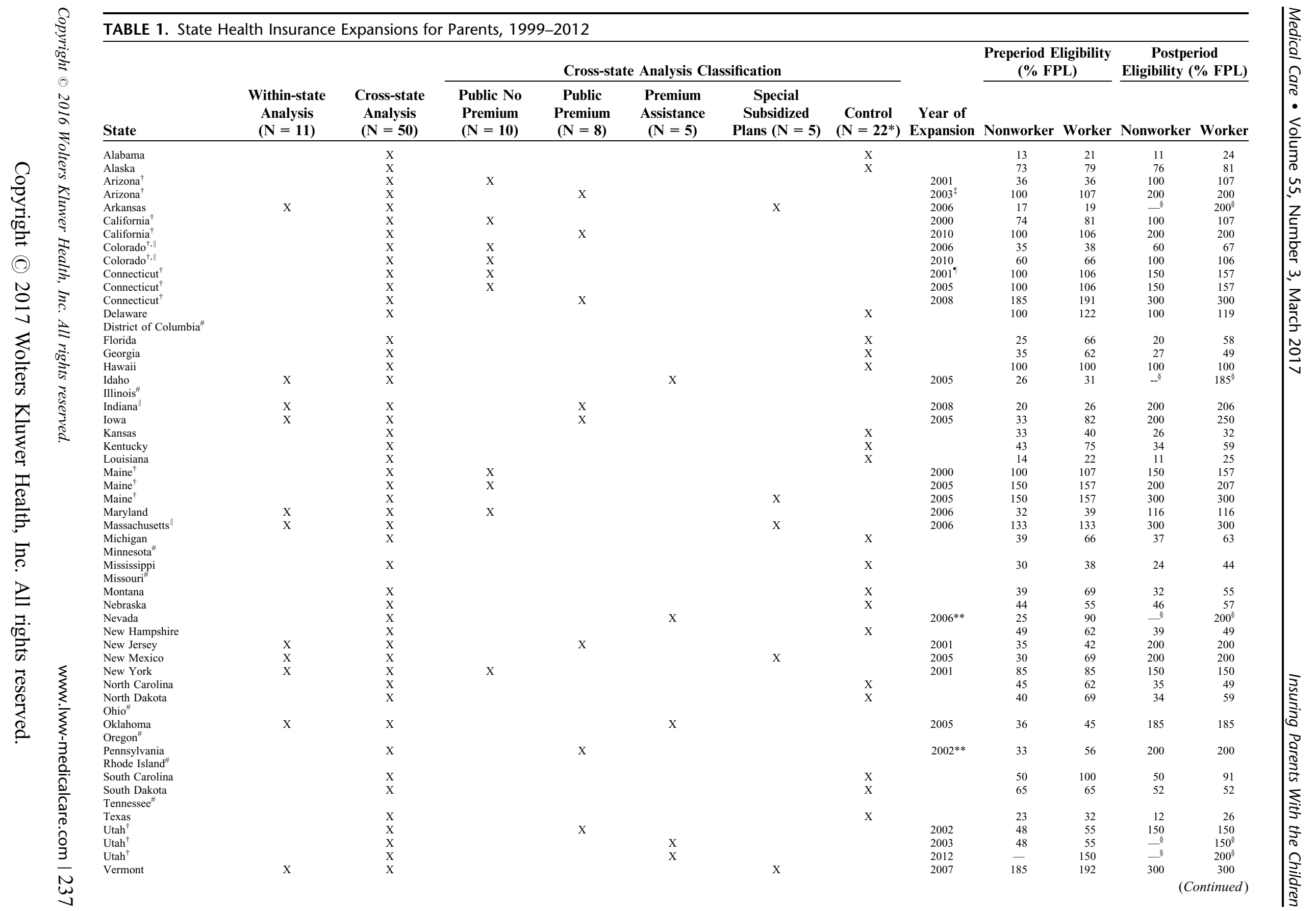




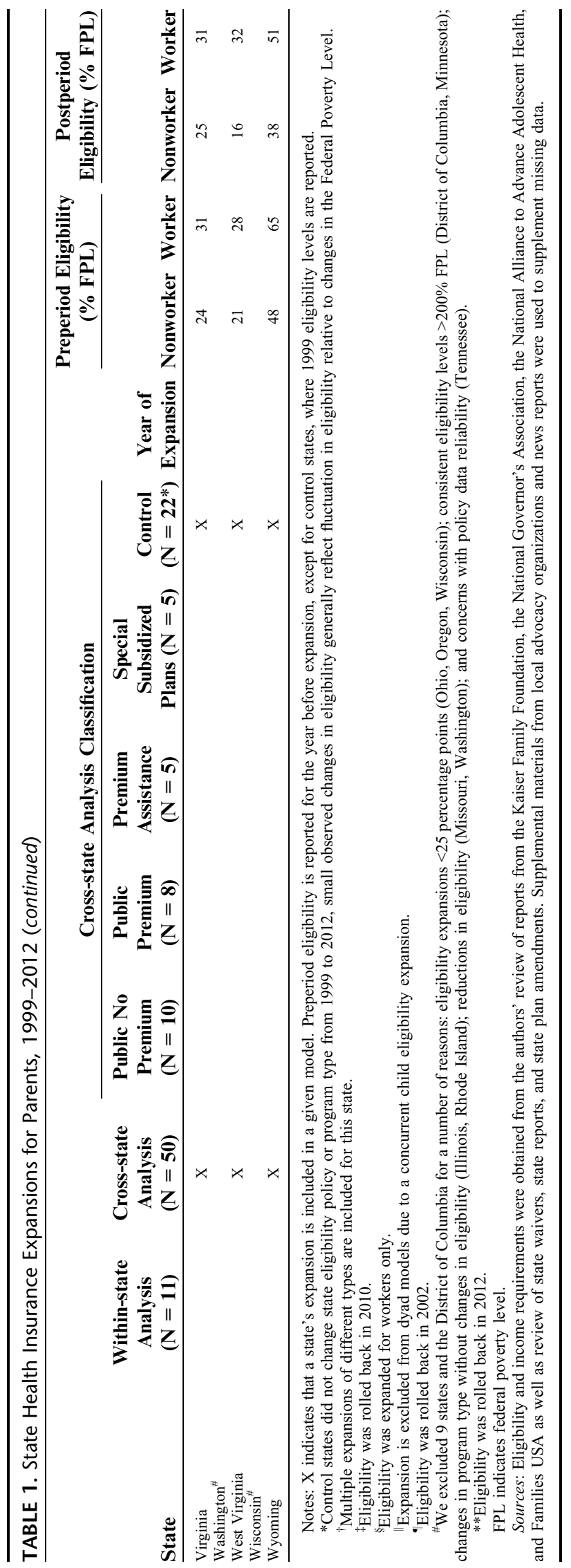

238 | www.Iww-medicalcare.com through spillover effects. The effect on children could be attributable to changes in the family budget that make purchasing child insurance possible or to parents enrolling previously eligible but unenrolled children when the parent enrolls. Evidence of such spillover effects has been demonstrated with parental Medicaid expansions but joint coverage has not been studied. ${ }^{14-16}$ Having a parent enrolled in public coverage also improves retention of children in Medicaid and the Children's Health Insurance Program (CHIP). ${ }^{4,5}$ States considering expansion under the ACA are doing so with the CHIP program still in place.

Prior state-level expansions to parents have taken a variety of forms. One approach has been to provide public health insurance, largely Medicaid but in some instances with limited benefits, either with or without an enrollee premium. However, premiums may result in lower enrollment in public coverage, shortened spells of enrollment, and an increased likelihood of being uninsured, ${ }^{17-23}$ particularly among individuals without access to employer-sponsored insurance (ESI). ${ }^{24}$ Providing subsidies for private health insurance is an additional approach to increase coverage among parents. Subsidy programs have been structured 2 ways. First, premium assistance programs provide subsidies for the purchase of ESI or coverage through the individual market. Second, special subsidized plans provide subsidies for the purchase of insurance through a specific state-offered plan or a limited number of state-selected managed care plans. The impact of these programs is less understood although some evidence suggests they may be effective in reducing uninsurance rates. ${ }^{20,25}$

Limited evidence exists on the impact of parental health insurance expansions on both parent and child insurance coverage, the differential effects of alternative expansion approaches, and the impact of public and private health insurance premiums on parents in income ranges affected by state expansions. This study seeks to fill these gaps by estimating the impact of previous parental health insurance expansions on the health insurance status of parents and their children. Knowledge about the effects of these expansions can shed important insight on the potential impact of expansions implemented and designed under the ACA as a large number of states consider the approach that is effective and politically acceptable to residents.

\section{METHODS}

\section{Design}

We used the 2000-2013 March supplements to the Current Population Survey (CPS), a large database with detailed demographic, socioeconomic, and employment characteristics among individuals in the United States. The March CPS includes state identifiers and detailed information on family income, making it possible to determine eligibility for health insurance expansions given each state's eligibility criteria. In addition, the March CPS includes information on health insurance coverage in the previous year. Additional data on private health insurance premiums were obtained from the Medical Expenditure Panel Survey 
Insurance Component, and county-level economic data were obtained from the Area Resource File.

We use variation in states' parental health insurance expansions from 1999 to 2012 to estimate the probability that parents are insured; their children are insured; both the parent and child within a family unit are insured; and both are insured publicly or privately. We used a hierarchy to assign one type of health insurance to each individual: those reporting private coverage, followed by public coverage, and uninsured. We examined the effect of expansions on the health insurance status of parents and their children using parent-child dyads, by randomly selecting a child age $\leq 18$ years for each parent. A random child was used in creating the dyads to avoid overrepresentation of multichild households. We excluded 3 states (Colorado, Indiana, Massachusetts) from all dyad analyses given concurrent eligibility expansions for parents and children in those states. Our analysis included all parental health insurance expansions $\geq 25$ percentage points of the FPL (Table 1). Our sample included parents aged $<65$ years without Medicare coverage.

\section{Cross-State Analysis}

In our cross-state analysis we exploit the variation in parental health insurance expansion implementation during our study period using 2-way fixed effects models. This methodology allows for the analysis of multiple expansions in a given state. We included dummy variables in the models that indicate the presence or absence of a parental health insurance expansion for each state-year based on the year of expansion implementation. We used multivariable logistic regression to estimate individual insurance coverage, and multinomial logistic regression to estimate insurance coverage among dyads.

The study sample for the cross-state models consisted of parents $\leq 300 \%$ FPL in the 19 expansion states (representing 28 expansions) and 22 control states without a parental expansion during the study period. We estimated the overall effect of an expansion, and the effect of each type of expansion (public insurance expansion without a premium, public insurance with a premium, premium assistance, and special subsidized plans). We excluded 9 states and the District of Columbia for a number of reasons (Table 1). The remaining 22 states were chosen as control states because they made no changes for parents from 1999 to 2012.

\section{Within-State Analysis}

Our within-state analysis examined the impact of parental health insurance expansions on insurance status using difference-in-difference modeling and a within-state control group. With difference-in-difference modeling, changes in the outcomes from the control group are subtracted from those of the treatment group, controlling for any groupspecific and time-specific effects that may have affected insurance status during the study years. The treatment group includes parents eligible for insurance expansions, whereas the control group consists of near eligible parents $\leq 300 \%$ of the FPL in expansion states. ${ }^{12,26}$ With this method, we were limited to states with one expansion $(n=11)$ during the study period (Table 1). We used logistic regression to estimate individual insurance coverage and multinomial logistic regression to estimate the joint insurance configuration among dyads.

\section{Impact of Premiums}

We used multinomial logistic regression models to estimate the impact of annual out-of-pocket public and private health insurance premiums for individual coverage on the probability of public insurance, private insurance, and uninsurance among parents. We obtained private insurance premiums from the Medical Expenditure Panel Survey Insurance Component by firm size/state/year level. We adjusted the premium by the likelihood an employee was offered coverage based on firm size to calculate out-ofpocket contributions, as previously done in the literature..$^{20,22}$ Those without a worker in the household were assigned the full premium. Public insurance premiums were obtained from a variety of sources (Table 1) and adjusted by income level if needed. As public premium levels are of increased importance among individuals without access to ESI, ${ }^{24}$ we also estimated separate models among parents with or without a worker in the household. We conducted the premium analysis among all parents eligible for an insurance expansion.

\section{Multivariable Analyses}

All regressions controlled for household, parent, child, and area-level characteristics that could affect insurance status. Household characteristics included family income, family size, and the presence of a child. Parent and child characteristics included age, sex, race/ethnicity, health status, disability status, and citizenship status. Additional parent characteristics included education, marital status, work status, firm size, and spousal work status. Area-level characteristics included urban/ rural status, county-level unemployment rate, and county-level per capita income. All analyses were conducted in Stata version 14.0, included state and year-fixed effects, and adjusted SEs for clustering at the state/year level.

\section{Sensitivity Analyses}

We examine a number of alternative models to test the sensitivity of our results to the analytic sample included. First, since the full effects of an eligibility expansion may not occur immediately, we estimate models excluding the expansion year in each state. Second, we estimate our models excluding noncitizen parents, as noncitizens may not be eligible for state parental health insurance expansions.

\section{RESULTS}

\section{Insurance Status Over Time}

During our study period, insurance coverage decreased by 2.4 percentage points among parents in expansion states, whereas insurance coverage decreased by 11.2 percentage points among parents in control states (Table 2). Among children, the percent insured increased by 5.5 percentage points among those in expansion states and by 3.4 percentage points among those in control states. The percent of dyads with both the parent and child uninsured fell by 4.3 percentage points among those in expansion states and by 2.2 
TABLE 2. Insurance Coverage Among Parents, Children, and Parent-child Dyads Among Eligible Parents, 1999 and 2012

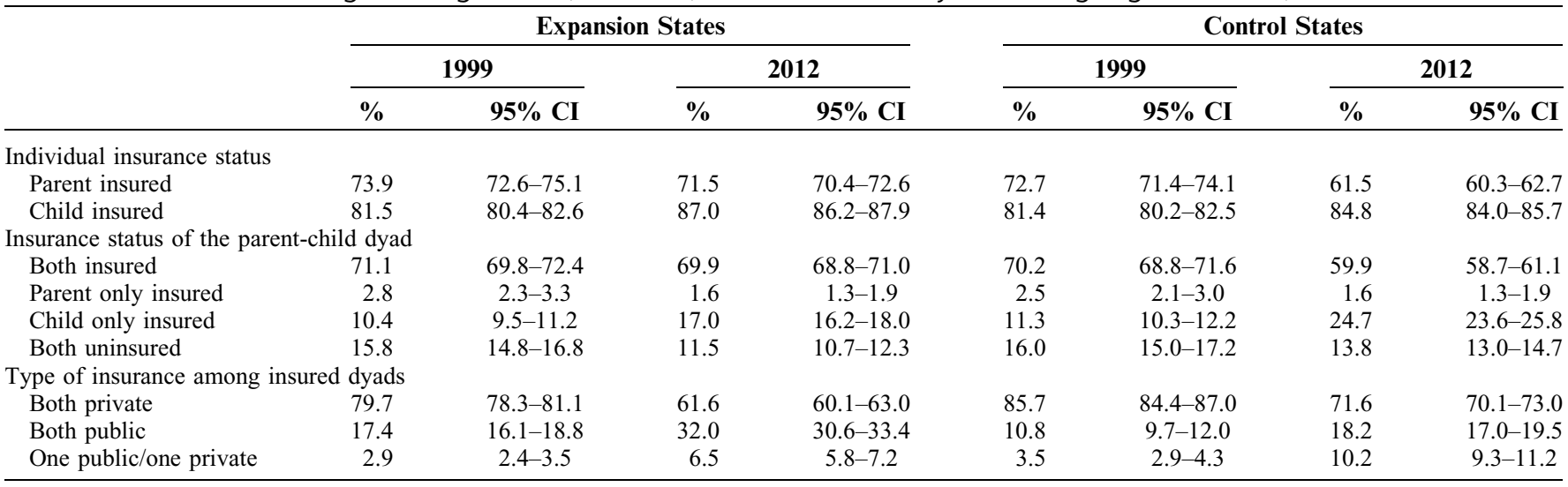

Sample includes parents up to $300 \%$ federal poverty level in the 19 expansion states and 22 control states without a parental expansion during the study period. CI indicates confidence interval.

percentage points among those in control states. The percent of dyads with the parent and child both covered with private insurance fell by 18.1 percentage points among those in expansion states and 14.1 percentage points among those in control states. At the same time, the percent of dyads with a publicly insured parent and child increased by 14.6 percentage points among dyads in expansion states and 7.4 percentage points among those in control states.

\section{Impact of Parental Insurance Expansions}

The cross-state models indicate that parental insurance expansions were associated with significant changes in coverage among parents and their children (Table 3). Across all types of expansions, these policies increased insurance coverage by 2.5 percentage points among parents, and increased the likelihood of both the parent and child being insured by 2.1 percentage points. The impact of parental expansions varied by expansion type, with the largest effect on parental insurance coverage found among public insurance expansions without a premium and special subsidized plan expansions, increasing parental coverage by 4.0 and 4.2 percentage points, respectively. Public insurance expansions without a premium and expansions using special subsidized plans also increased the likelihood that the parent and child were insured by 4.8 and 3.1 percentage points, respectively, while no significant effect was observed for other expansion types. In addition, there was weak evidence that parental public insurance expansions without a premium increased coverage among children, while no significant effect for children was found among other expansions types.

Among insured dyads, the expansions increased the likelihood that both the parent and child were covered with public insurance by 1.4 percentage points, and deceased the likelihood that both were privately insured by 1.0 percentage points. This finding suggests that some type of "crowd out" is occurring among insured dyads, with a shift in the source of joint coverage away from private insurance and towards public insurance. This impact varied by expansion type. The largest increases in joint public insurance were observed among public insurance expansions without a premium and special subsidized plan expansions, with increases of 3.1 and 1.3 percentage points, respectively.

Consistent with our findings in the cross-state models, the within-state analysis indicates that parental insurance expansions were associated with significant changes in coverage among parents and importantly, indicate significant effects for their children (Table 4). The expansions increased insurance coverage by 3.1 percentage points for newly eligible parents, increased coverage by 1.8 percentage points for their children, and increased the likelihood of both the parent and child being insured by 2.1 percentage points.

\section{Impact of Premiums}

The average annual public health insurance premium faced by eligible parents was $\$ 150$ (including those without a public premium), while the average private health insurance premium for individual coverage was $\$ 2450$ (data not shown). A $\$ 500$ increase in the annual public premium decreased the probability of public insurance by 1.9 percentage points, increased the probability of private insurance by 1.2 percentage points, and increased the probability of being uninsured by 0.6 percentage points (Table 5). Meanwhile, a $\$ 500$ increase in private premiums decreased the probability of private insurance by 1.2 percentage points, increased the probability of public insurance by 0.8 percentage points, and increased the probability of being uninsured by 0.5 percentage points.

The impact of public and private premiums varied based on the presence of a worker in the household. Among parents with a worker in the household, private premiums had a substantial impact on insurance status. A \$500 increase in private premiums decreased the probability of private insurance by 3.3 percentage points, increased the probability of public insurance by 1.0 percentage points, and increased the probability of being uninsured by 2.4 percentage points. Among parents without a worker in the household, private premiums did not have a significant impact on insurance status, while public premiums had a substantial impact. 
TABLE 3. Effects of Parent Expansions on Insurance Status-Cross-state Models

\section{Type of Expansion ${ }^{\dagger}$}

\begin{tabular}{|c|c|c|c|c|c|c|c|c|c|c|}
\hline & \multicolumn{2}{|c|}{ Overall* } & \multicolumn{2}{|c|}{$\begin{array}{c}\text { Public Insurance } \\
\text { Without a Premium }\end{array}$} & \multicolumn{2}{|c|}{$\begin{array}{l}\text { Public Insurance } \\
\text { With a Premium }\end{array}$} & \multicolumn{2}{|c|}{ Premium Assistance } & \multicolumn{2}{|c|}{$\begin{array}{c}\text { Special Subsidized } \\
\text { Plans } \\
\end{array}$} \\
\hline & $\begin{array}{c}\text { Marginal } \\
\text { Effect }\end{array}$ & $P$ & $\begin{array}{c}\text { Marginal } \\
\text { Effect }\end{array}$ & $\boldsymbol{P}$ & $\begin{array}{l}\text { Marginal } \\
\text { Effect }\end{array}$ & $\boldsymbol{P}$ & $\begin{array}{c}\text { Marginal } \\
\text { Effect }\end{array}$ & $P$ & $\begin{array}{c}\text { Marginal } \\
\text { Effect }\end{array}$ & $P$ \\
\hline \multicolumn{11}{|c|}{ Individual insurance status } \\
\hline Parent insured & 0.025 & $<0.001$ & 0.040 & $<0.001$ & 0.009 & 0.068 & 0.017 & 0.038 & 0.042 & $<0.001$ \\
\hline Child insured & 0.002 & 0.715 & 0.018 & 0.094 & -0.007 & 0.188 & -0.001 & 0.908 & 0.005 & 0.561 \\
\hline \multicolumn{11}{|c|}{ Insurance status of the parent-child dyad } \\
\hline Child only insured & -0.018 & $<0.001$ & -0.030 & 0.003 & -0.010 & 0.024 & -0.011 & 0.099 & -0.026 & 0.002 \\
\hline Both uninsured & -0.005 & 0.366 & -0.018 & 0.046 & 0.002 & 0.701 & -0.002 & 0.811 & -0.005 & 0.539 \\
\hline \multicolumn{11}{|c|}{ Type of insurance among insured dyads } \\
\hline Both private & -0.010 & 0.032 & -0.009 & 0.232 & -0.004 & 0.490 & 0.008 & 0.356 & -0.011 & 0.160 \\
\hline Both Public & 0.014 & 0.004 & 0.031 & 0.001 & 0.002 & 0.761 & 0.001 & 0.835 & 0.013 & 0.044 \\
\hline $\begin{array}{l}\text { One public/one } \\
\text { private }\end{array}$ & -0.004 & 0.390 & -0.022 & 0.039 & 0.002 & 0.612 & -0.010 & 0.144 & -0.001 & 0.814 \\
\hline
\end{tabular}

Sample includes parents and parent/child dyads up to $300 \%$ federal poverty level in the 19 expansion states and 22 control states without a parental expansion during the study

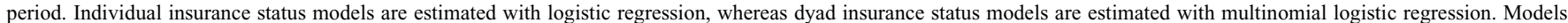

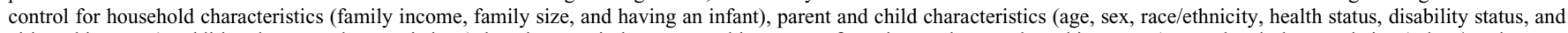

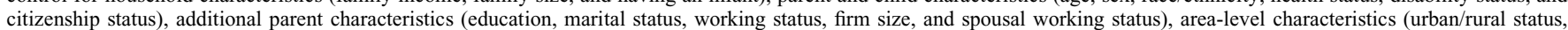
county-level unemployment rate, and county-level per capita income), and state and year-fixed effects.

*Model specification: InsuranceStatus ${ }_{i j t}=\beta_{0}+\beta_{1}$ Expansion $_{i j t}+\beta_{2} X_{i j t}+\gamma$ State $_{j}+\theta$ Year $_{t}+\epsilon_{i j t}$

${ }^{\dagger}$ Model specification: InsuranceStatus ${ }_{i j t}=\beta_{0}+\beta_{1}$ PublicPrem $_{i j t}+\beta_{2}$ PublicNoPrem $_{i j}+\beta_{3}$ PremAst ${ }_{3} \beta_{4}$ SpSubPlan $+\beta_{5} X_{i j t}+\gamma$ State $_{j}+\theta$ Year $_{t}+\epsilon_{i j t}$

PublicPrem indicates Public Insurance With a Premium; PublicNoPrem, Public Insurance Without a Premium; PremAst, Premium Assistance; SpSubPlan, Special Subsidized Plans.

Specifically, a $\$ 500$ increase in public premiums decreased the probability of public insurance by 9.8 percentage points, increased the probability of private insurance by 2.9 percentage points, and increased the probability of being uninsured by 6.9 percentage points.

TABLE 4. Effects of Parent Expansions on Insurance StatusWithin-state Models

\begin{tabular}{lcr}
\hline & \multicolumn{2}{c}{ Overall } \\
\cline { 2 - 3 } & Marginal Effect & $\boldsymbol{P}$ \\
\hline Individual insurance status & & \\
$\quad$ Parent insured & 0.031 & 0.001 \\
$\quad$ Child insured & 0.018 & 0.029 \\
Insurance status of the parent-child dyad & & \\
$\quad$ Both insured & 0.021 & 0.036 \\
$\quad$ Parent only insured & 0.002 & 0.535 \\
Child only insured & -0.005 & 0.598 \\
Both uninsured & -0.018 & 0.012 \\
Type of insurance among insured dyads & & 0.604 \\
$\quad$ Both private & 0.006 & 0.949 \\
$\quad$ Both public & -0.001 & 0.521 \\
$\quad$ One public/one private & -0.006 & \\
\hline
\end{tabular}

Sample includes parents in expansion states who became eligible for the public health insurance expansions, and similar parents who were not eligible for the expansion with income higher than the eligibility level (up to $300 \%$ federal poverty level). Individual insurance status models are estimated with logistic regression, while dyad insurance status models are estimated with multinomial logistic regression. Models control for household characteristics (family income, family size, and having an infant), parent and child characteristics (age, sex, race/ethnicity, health status, disability status, and citizenship status), additional parent characteristics (education, marital status, working status, firm size, and spousal working status), area-level characteristics (urban/rural status, county-level unemployment rate, and county-level per capita income), and state and year-fixed effects.

Model specification: InsuranceStatus ${ }_{i j t}=\beta_{0}+\beta_{1}$ Post $_{i j t}+\beta_{2}$ Eligible $_{i j}+\beta_{3}$ Post Eligible $_{i j t}+$ $\beta_{4} X_{i j t}+\gamma$ State $_{j}+\theta$ Year $_{t}+\epsilon_{i j t}$

\section{Sensitivity Analyses}

Overall, the various sensitivity checks showed the same pattern of results, implying a generally robust relationship between parental insurance expansions and health insurance status regardless of the analytic sample included. In our models excluding the initial year of expansions, we find similar patterns, but larger magnitudes. This suggests that the effects of the parental expansions may take some time to be fully realized.

\section{DISCUSSION}

Our analysis found that recent health insurance expansions among parents were effective in increasing health insurance coverage among both parents and their children, but that these effects varied by the type of expansion used by the state. The most effective expansions for parental insurance coverage were those for traditional Medicaid coverage without premiums and for special subsidized plans that subsidized costs for individuals to purchase state-sponsored plans. The subsidization of state-sponsored plans is the expansion type most analogous to states' (most notably Arkansas) use of waiver authority to use federal Medicaid expansion funds to purchase qualified health plan coverage for newly Medicaid-eligible individuals through the Health Insurance Marketplace. While the Southern states have been slow to expand under the ACA provisions, some states may be "watching" the Arkansas experiment as a politically feasible approach in their state.

The relative effects of these expansions for parents on parental insurance coverage, 4.0 percentage points for traditional Medicaid and 4.2 percentage points for state-sponsored 
TABLE 5. Marginal Effects of a $\$ 500$ Increase in Public and Private Premiums on Parent Health Insurance Status

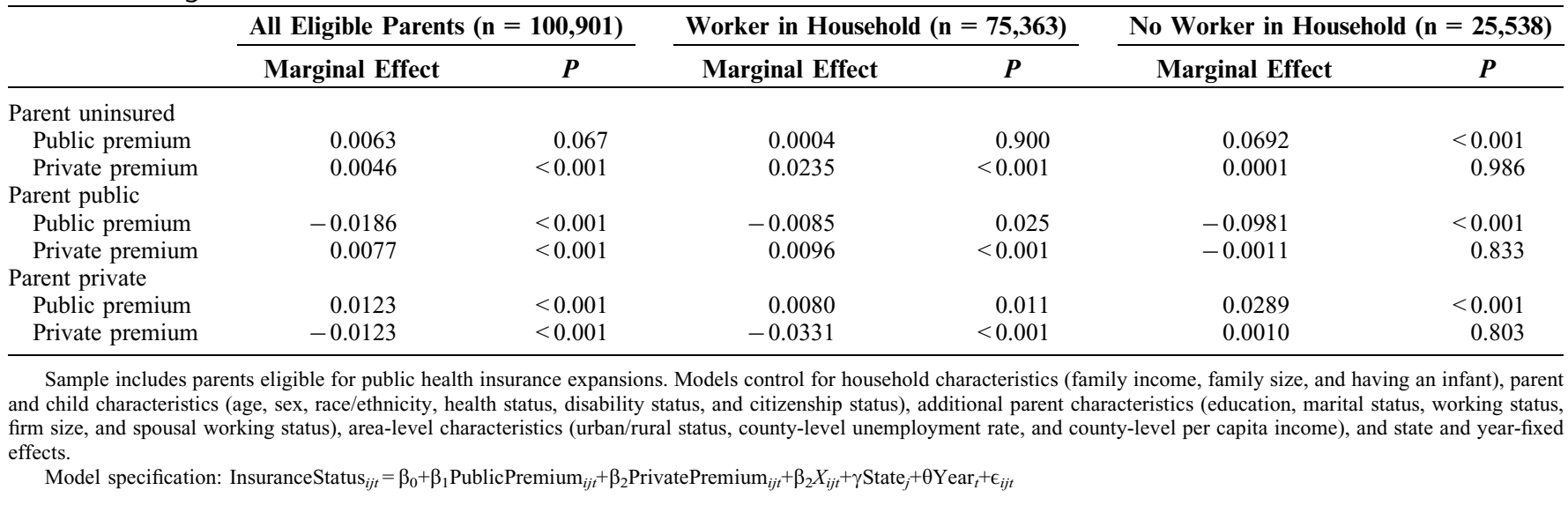

plans, suggests that states using Section 1115 or other waivers to purchase coverage in special subsidized plans for low-income residents through the Marketplace will increase parental coverage perhaps as effectively as traditional Medicaid. Similar findings were also observed for joint parent and child coverage, in which public insurance without a premium and special subsidized plan expansions increased the likelihood of joint coverage among parents and their children. However, the effects of parental expansions on child coverage were mixed. Although the within-state models indicate that parental expansions increase the likelihood of child coverage, only weak effects were observed in the across state models and were limited to parental expansions of public insurance without a premium. Together, these findings suggest that the effect of parental health insurance expansions on increased coverage among children may be confined to parental expansions using the traditional Medicaid program.

The relative costs to both federal and state governments of these 2 types of expansions might mean one is more cost-effective than the other in terms of covering families. One argument for using premium assistance for Qualified Health Plans, for example, is reduced "churning" between public and private insurance sectors and, hence, reduced costs to taxpayers; a form of this hypothesis is being tested in 2 states (Arkansas and Iowa) at this time. ${ }^{27}$ States with these waivers claim budget neutrality, arguing that the state would have had to increase Medicaid physician reimbursement rates to private rates to assure access for new enrollees, and that these states might be able to eventually set lower capitated payment rates for managed care plans since they will have a larger and more stable clientele. However, our finding that expansions designed as public programs without premiums targeting parents can also increase coverage among children should enter into this policy deliberation.

Another important consideration for insuring both parent and child is the so-called "family glitch." Determination of whether an employee's offered ESI plan is "affordable" is based only on the costs of an individual insurance plan. If an individual plan is determined to be affordable, that employee is unable to receive federal subsidies for family coverage through the marketplace, even if family coverage offered by their employer is unaffordable. This "glitch" may result in parents purchasing the "affordable" individual ESI plan for themselves and not covering their child through ESI. In such instances, CHIP serves an important role of providing public coverage for an otherwise uninsured child. In states with relatively lower CHIP income eligibility levels, however, parents may have no subsidized coverage option for their child. Moreover, if CHIP is not renewed in 2017 these parents would face large increases in the costs of obtaining child coverage because they are not eligible for subsidies. Parents without access to ESI could take advantage of the subsidies but would typically still face higher costs for coverage than the current generally modest CHIP premiums for their child. State designed buy-in options could address this issue for families, especially those in the $139 \%-200 \%$ FPL income range for which states can use the BHP option.

Our findings also provide information regarding the impact of premiums on the insurance status of parents. Among parents, higher public premiums were associated with a reduction in public insurance, and increased the likelihood of private insurance or being uninsured. This impact varied however, based on the presence of a worker in the household. Although parents without a worker in the household are a relatively small percentage of all parents, private premiums had no measureable impact on the likelihood of being insured among this population. Public premiums, however, were a significant deterrent to coverage for parents in nonworker households, and had effects on public coverage that were $>10$ times as large as the effects among working families. Among parents with a worker in the household, both the public and private premiums had a significant impact on insurance status; policymakers will need to assess the rate of increase in private premiums for their effects on parents, particularly those purchasing in the marketplace.

This analysis has limitations. Although the CPS is a standard dataset to measure insurance status, it may be subject to error. Individuals are asked in March about 
insurance coverage during the preceding year, which may result in respondents erroneously reporting their coverage during the current year. Moreover, participant-reported distinctions between public coverage and nongroup private coverage may not be reliable, especially for plans administered for the states by private insurance carriers or networks of providers. We use annual income measures to determine expansion eligibility, but administrative determinations of eligibility consider income at a specific point in time. Our reliance on imputed health insurance premiums may introduce measurement error into our analysis. Lastly, the generalizability of our findings maybe limited given some key differences between our expansions and those under the ACA, namely the presence of the individual mandate and online eligibility systems.

Our analysis shows that expansions of public coverage without premiums for parents are successful at not only insuring parents, but may also increase insurance coverage among their children. This indicates that states expanding Medicaid for newly eligible adults under the ACA will see greater increases in insurance coverage for children than nonexpanding states. Our results suggest that using section 1115 or eventually, 1332 waivers to provide subsidies for the purchase of coverage through special subsidized plans for low-income residents through the Health Insurance Marketplace is an effective alternative option for increasing parental coverage, but might not result in higher coverage rates for children. Whether this approach is cost-effective needs to be evaluated. Putting states in control of the subsidy structure under 1115 or 1332 waiver options or use of the BHP option for families with incomes $139-200 \%$ FPL could moderate the impact of the family glitch inherent in current Internal Revenue service regulations regarding the ACA-based subsidies by creating alternative pathways to joint coverage of parents and children.

\section{REFERENCES}

1. Davidoff A, Dubay L, Kenney G, et al. The effect of parents' insurance coverage on access to care for low-income children. Inquiry. $2003 ; 40: 254-268$

2. DeVoe JE, Tillotson CJ, Wallace LS. Children's receipt of health care services and family health insurance patterns. Ann Fam Med. 2009;7:406-413.

3. DeVoe JE, Tillotson CJ, Wallace LS, et al. Parent and child usual source of care and children's receipt of health care services. Ann Fam Med. 2011;9:504-513.

4. Yamauchi M, Carlson MJ, Wright BJ, et al. Does health insurance continuity among low-income adults impact their children's insurance coverage? Matern Child Health J. 2013;17:248-255.

5. Sommers BD. Insuring children or insuring families: do parental and sibling coverage lead to improved retention of children in Medicaid and CHIP? J Health Econ. 2006;25:1154-1169.
6. Chrisler J, McCreary D. Handbook of Gender Research in Psychology (No 2). New York, NY: Springer; 2010.

7. Busch SH, Duchovny N. Family coverage expansions: Impact on insurance coverage and health care utilization of parents. $J$ Health Econ. $2005 ; 24: 876-890$

8. Hamersma S, Kim M. Participation and crowd out: assessing the effects of parental Medicaid expansions. J Health Econ. 2013;32:160-171.

9. Kronick R, Gilmer T. Insuring low-income adults: does public coverage crowd out private? Health Aff (Millwood). 2002;21:225-239.

10. Wolfe B, Kaplan T, Haveman R, et al. SCHIP expansion and parental coverage: an evaluation of Wisconsin's BadgerCare. J Health Econ. 2006;25:1170-1192.

11. Sommers BD, Baicker K, Epstein AM. Mortality and access to care among adults after state Medicaid expansions. N Engl J Med. 2012;367: 1025-1034.

12. Atherly A, Dowd BE, Coulam RF, et al. The effect of HIFA waiver expansions on uninsurance rates in adult populations. Health Serv Res. 2012;47(3pt1):939-962.

13. McMorrow S, Kenney GM, Long SK, et al. Medicaid expansions from 1997 to 2009 increased coverage and improved access and mental health outcomes for low-income parents. Health Serv Res. 2016;51:1347-1367.

14. Dubay L, Kenney G. Expanding public health insurance to parents: effects on children's coverage under Medicaid. Health Serv Res. 2003; 38:1283-1302.

15. Dubay L, Kenney G. Addressing coverage gaps for low-income parents. Health Aff (Millwood). 2004;23:225-234.

16. DeVoe JE, Marino M, Angier H, et al. Effect of expanding medicaid for parents on children's health insurance coverage: Lessons from the oregon experiment. JAMA Pediatrics. 2015;169:e143145.

17. Kenney G, Marton J, McFeeters J, et al. Assessing potential enrollment and budgetary effects of SCHIP premiums: findings from Arizona and Kentucky. Health Serv Res. 2007;42(6p2):2354-2372.

18. $\mathrm{Ku} \mathrm{L}$, Coughlin TA. Sliding-scale premium health insurance programs: four states' experiences. Inquiry. 1999;36:471-480.

19. Dague L. The effect of Medicaid premiums on enrollment: a regression discontinuity approach. $J$ Health Econ. 2014;37:1-12.

20. Guy GP Jr, Adams EK, Atherly A. Public and private health insurance premiums: how do they affect the health insurance status of low-income childless adults? Inquiry. 2012;49:52-64.

21. Hadley J, Reschovsky JD, Cunningham P, et al. Insurance premiums and insurance coverage of near-poor children. Inquiry. 2006;43: 362-377.

22. Kenney G, Hadley J, Blavin F. Effects of public premiums on children's health insurance coverage: evidence from 1999 to 2003. Inquiry. 2006; 43:345-361.

23. Marton J, Ketsche PG, Snyder A, et al. Estimating premium sensitivity for Children's Public Health Insurance Coverage: selection but no death spiral. Health Serv Res. 2015;50:579-598.

24. Abdus S, Hudson J, Hill SC, et al. Children's health insurance program premiums adversely affect enrollment, especially among lower-income children. Health Aff (Millwood). 2014:33:1353-1360.

25. Atherly A, Call K, Coulam R, et al. Medicaid expansions and crowdout: evidence from HIFA premium assistance programs. Health Serv Res. 2016;51:117-128.

26. Goldstein IM, Kostova D, Foltz JL, et al. The impact of recent CHIP eligibility expansions on children's insurance coverage, 2008-12. Health Aff (Millwood). 2014;33:1861-1867.

27. Sommers BD, Gourevitch R, Maylone B, et al. Insurance churning rates for low-income adults under health reform: lower than expected but still harmful for many. Health Aff. 2016;35:1816-1824. 